Case Report

\title{
Innovative Methods for Small Mixed Batches Production System Improvement: The Case of a Bakery Machine Manufacturer
}

\author{
Kristina Zgodavova ${ }^{1, *(\mathbb{D}}$, Peter Bober ${ }^{2, *} \mathbb{D}$, Vidosav Majstorovic ${ }^{3}\left(\mathbb{D}\right.$, Katarina Monkova $^{4}(\mathbb{D}$, \\ Gilberto Santos ${ }^{5}{ }^{\circ}$ and Darina Juhaszova ${ }^{1}$ \\ 1 Faculty of Materials, Metallurgy and Recycling, Technical University of Košice, 04200 Košice, Slovakia; \\ darina.juhaszova@student.tuke.sk \\ 2 Faculty of Electrical Engineering and Informatics, Technical University of Košice, 04200 Košice, Slovakia \\ 3 Faculty of Mechanical Engineering, University of Belgrade, 11000 Belgrade, Serbia; \\ vidosav.majstorovic@sbb.rs \\ 4 Faculty of Manufacturing Technologies, Technical University of Košice, 08001 Prešov, Slovakia; \\ katarina.monkova@tuke.sk \\ 5 School of Design, Polytechnic Institute Cavado Ave, Campus do IPCA, 4750-810 Barcelos, Portugal; \\ gsantos@ipca.pt \\ * Correspondence: kristina.zgodavova@tuke.sk (K.Z.); peter.bober@tuke.sk (P.B.); \\ Tel.: +421-903-750-590 (K.Z.); +421-55-602-2281 (P.B.)
}

Received: 3 July 2020; Accepted: 31 July 2020; Published: 4 August 2020

\begin{abstract}
One of the common problems of organizations with turn-key projects is the high scrap rate. There exist such traditional methods as Lean Six Sigma (LSS) and DMAIC tools that analyze causes and suggest solutions. New emerging intelligent technologies should influence these methods and tools as they affect many areas of our life. The purpose of this paper is to present the innovative Small Mixed Batches (SMB). The standard set of LSS tools is extended by intelligent technologies such as artificial neural networks (ANN) and machine learning. The proposed method uses the data-driven quality strategy to improve the turning process at the bakery machine manufacturer. The case study shows the step-by-step DMAIC procedure of critical to quality (CTQ) characteristics improvement. Findings from the data analysis lead to a change of measurement instrument, training of operators, and lathe machine set-up correction. However, the scrap rate did not decrease significantly. Therefore the advanced mathematical model based on ANN was built. This model predicts the CTQ characteristics from the inspection certificate of the input material. The prediction model is a part of a newly designed process control scheme using machine learning algorithms to reduce the variability even for input material with different properties from new suppliers. Further research will be focused on the validation of the proposed control scheme, and acquired experiences will be used to support business sustainability.
\end{abstract}

Keywords: artificial neural network; lean six sigma; machine learning; process capability; small mixed batches; turning process

\section{Introduction}

The rapidly changing economic and market environment and increasing pressure for a sustainable lifestyle bring changes in the behavior and the habits of people. Machines for the macroscopic world are being developed [1]. Similarly, engineering can produce at the precision level of microns, and measurement technologies have shifted to high-sensitive optical sensors and imaging technologies. This changing environment places new demands on innovation and change, but most industrial 
organizations, according to the survey [2,3], are not yet in a state where they would introduce intelligent technologies. These technologies, in the context of Quality 4.0, allow the processing and presentation of a large amount of data from past measurements that can be used to look back for the trends and forward-looking decision making [4,5], where new business can appear based on new technologies [6], aiming at value creation [7] with increasingly demanding customers.

Despite these possibilities, many non-automotive industry organizations still record their measurements in paper forms and underuse the power of data to reduce material and energy consumption, which is a necessary condition for sustainability on the organizational level [8]. Moreover, bakery machine manufacturers have to keep up with this reality and continuously innovate their activities, change the product portfolio, and improve the quality and performance of processes, but all within the principles of hygienic design of the bakery machine [9]; although, in many cases, they produce machine components in small mixed batches according to individual customer requirements (custom made bakery machines). There is no remaining time or financial opportunities for $100 \%$ quality inspection of all characteristics of manufactured parts. Therefore, process engineers and quality engineers must be able to monitor the critical to quality (CTQ) characteristics, process quality, and performance indicators in real-time and must be able to use tools of advanced quality improvement to ensure that the production process is stable and efficient $[10,11]$. Research on processes with low repeatability and small mixed batches has, in the past, been focused mainly on products and less on processes. That is, quality has been studied only on final parts or products [12].

The presented case study relates to an organization that has not analyzed the process capability and performance in the past; it relied mainly on production time standards and the skills of operators. Nowadays, the necessity to modify production towards more sustainable business and according to individual customer specifications and preferences, the "Lean" paradigm $[13,14]$ and Six Sigma philosophy, is increasingly being applied, because organizations need to focus on process improvement $[15,16]$.

Our research aims to propose a sequence of quality improvement steps related to the implementation of Lean Six Sigma (LSS) tools and intelligent technologies for Small Mixed Batch (SMB) production. In the case study of a bakery machine manufacturer, the newly developed Lean Six Sigma Small Mixed Batch (LSS-SMB) method with machine learning methodology is applied. The goal of the case organization is to improve the turning process capability $(\mathrm{Cp})$.

The rest of the paper is structured as follows: Section 2 contains the literature survey of tools and methods used for SMB production system improvement with a focus on using intelligent technologies. Section 3 describes the problem in the bakery machine manufacturer and introduces the newly developed LSS-SMB method. This section also contains a detailed description of data collection and analysis during the two years of project duration. In Section 4, we continue by presenting the key results of our case study with the support of tables and figures. Section 5 discusses our findings, and Section 6 presents the key conclusions from the entire paper.

\section{Context: Tools and Methods Used for Small Mixed Batch Production System Improvement}

The volume of data available for research in recent years is exponentially growing [17]. Therefore, most businesses try to gain value from them. Data and analytics are changing the basis of competition, and companies are using analytical capabilities to launch brand new business and process models. Regarding quality management, access to data and information has also changed. The desired results are more likely to be achieved if decisions are based on the analysis and evaluation of data from the documented information [18]. The use of information from various existing organization databases in connection with Lean manufacturing principles translates the organization's performance into higher productivity, less invested time, better quality, customer satisfaction, increased sales and, consequently, increased profit [19]. Currently, the use of Lean tools in the manufacturing industry has been remarkably expanded thanks to using extensive data analysis that has impressive power to 
detect non-conformances, reduce waste and delivery times and lead the organization to streamlined manufacturing and value stream mapping [20].

Our research started with a literary survey, which contained keywords and abstracts related to: "Six Sigma"; "Lean"; "Small Mixed Batch"; "Statistical Process Control" and, applying intelligent technologies for Quality 4.0, "machine learning"; "machine vision". To ensure better search inclusion, phrase variants "Statistical Process Control" and "SPC", "Six Sigma" and "Lean Six Sigma", were used. There was initially no search restriction in the release year to avoid the arbitrary exclusion of resources. The results have been examined in more detail by keyword and thematic focus, and a group of papers was selected and sorted by years of occurrence. In particular, those related to industrial production and intelligent technologies were used in further research. Findings are summarized in the following three Sections.

\subsection{Six Sigma, Lean and Intelligent Technologies}

Selecting the right analytical tools to understand data to work with is a difficult task for experts. In industrial practice, the Six Sigma methodology is often used. It combines analytical and statistical quality tools and offers a universally applicable method of gradual improvement, which is an integral part of it. Lean Manufacturing is a system for maximizing product value for the customer while minimizing waste without reducing productivity. The synthesis of Lean Manufacturing with Six Sigma creates a comprehensive system that removes waste and reduces process variation and optimizes product output [21]. The high-level problem-solving approach in Lean Six Sigma is a 5-steps process called DMAIC (Define, Measure, Analyze, Improve, Control) [22]. Data analysis in Lean Six Sigma is typically historical in nature because data are gathered and analyzed after processes have run. Even in the control phase, when active process management is ongoing, data analysis occurs after the manufacturing rather than as the process runs [23].

Current intelligent technologies related to Quality 4.0 enable real-time process control and decision-making. Machine learning as a sub-set of artificial intelligence that provides systems with the ability to automatically learn and improve from experience without being explicitly programmed. Several researchers use machine vision [24], machine learning [25] and artificial neural networks (ANN) [26] for prediction of dimensional deviation and surface roughness. However, these intelligent technologies and real-time quality control and improvement are not yet an integral part of LSS practice.

\subsection{Small Mixed Batches, Short Run, and Statistical Process Control}

The term "small mixed batch" is used when different products are in the batch, but according to some characteristics, they can be investigated together [12]. The term "short-run" (SR) means that only a few pieces are produced, and consequently, a different part or item is going to be produced. It means that the production cycle is very short, or it does not allow intervention within a reasonable time; the repeatability of the production batch is low, and a very small volume of items is in a batch.

Statistical process control (SPC) techniques are applicable in any small mixed batch or short-run production, which are repeatable in any way [27]. The primary tool of the SPC is a control chart that shows the evolution of process variability over time.

For the application of control charts to SMB, process measurements from different products should be grouped. The procedure for the grouping of similar processes is described in [12]. It is necessary to regularly verify that data grouping for small mixed batch SPC is still valid. To flexibly group and reorganize operations, it is essential to record meta-data along with the measured data so that each measured value is associated with a group of processes [28].

The concept of intelligent SPC uses gathered data, artificial neural networks, and machine learning to improve the automatic detection of the out of control state of the process, or to estimate the process's mean value and variance [29-31]. The authors use intelligent technologies only for the detection of an adverse condition, but not for its prediction or prevention. To flexibly group and reorganize 
operations, it is essential to record meta-data along with the measured data so that each measured value is associated with a group of processes.

\subsection{Dimensional Deviation and Surface Roughness Prediction}

The ability to predict the surface quality before machining gives manufacturers an advantage in terms of cost-saving, shorter cycle time, and less re-work or rejects [32]. Several advanced approaches have been applied to develop the methodology of the dimensional tolerances and surface roughness prediction:

- Response surface methodology (RSM) in combination with the design of experiments (DOE) or regression analysis is used to develop a mathematical model for predicting surface roughness for a given set of input parameters. Mathematical modelling was used for the turning process in $[33,34]$.

- Artificial intelligence methods, particularly neural networks, can be applied to predict surface roughness and dimensional deviation based on the input variables $[26,35,36]$. Radial basis function (RBF) as a tool for prediction has been used by several authors [37-39].

In recent years, the development of machine vision hardware and advanced image processing technology has opened new possibilities in the field of tool condition monitoring and geometrical properties measurement of the workpiece without removing the workpiece from the lathe machine [40]. There are three commonly used technologies in optical shaft measurement systems: high-resolution matrix array, CCD cameras, and line scan technology [41].

Classical statistics and Lean Six Sigma have shown that if input variables have large variance, we would expect a large variance in the output variable(s). Finding a suitable approximation for the proper functional relationship $y=f(X)$ between the response of interest $y$ and a set of input variables $X=\left\{x_{i}, x_{2}, \ldots, x_{n}\right\}$, e.g., a response surface method (RSM) according to [33] can be used. Generally, if the response function is not known or is non-linear, a second-order model is utilized [42] in the form of Equation (1):

$$
y=b_{0}+\sum_{i=1}^{n} b_{i} x_{i}+\sum_{i=1}^{n} b_{i i} x_{i}^{2}+\sum_{i<j}^{n} b_{i j} x_{i} x_{j}+\varepsilon
$$

where $\varepsilon$ represents the noise or error observed in the response $y$ such that the expected response is $(y-\varepsilon)$ and $b$ s are the regression coefficients to be estimated.

The least-square technique can be used to fit a model equation containing input variables by minimizing the residual error measured by the sum of squared deviations between the actual and estimated responses. The calculated coefficients or the model equations, however, need to be tested for statistical significance.

According to [39], due to the inadequacy and inefficiency of the analytical models to explain the non-linear properties existing between machining parameters, intelligent systems such as ANN, fuzzy logic, and expert systems have emerged. ANN is an appropriate technique used to handle the problem of non-linearity. ANNs trained with a backpropagation algorithm can be used according to $[39,43]$ to predict optimal machine set-up. The feedforward backpropagation neural network [44] is applied in many cases when it is necessary to determine the output in terms of reliability, accuracy, and efficiency. The ANN defines a mapping $y=f(X ; \theta)$ and learns parameters $\theta=\{w, b\}$ to accomplish the best function approximation. Figure 1 shows the structure of the neural network with $n$ input variables, one hidden layer with $m$ neurons, and the output layer with one neuron. The parameters $\theta$ of a neural network are weights $w_{i j}$ and biases $b_{k}$. Each neuron $j$ calculates its output Equation (2):

$$
y_{j}=f_{a}\left(\sum_{i=1}^{n}\left(w_{i j}+b_{j}\right)\right)
$$


where $f_{a}$ is a neuron activation function. The learning algorithm uses a training set $T=\{(X, y)\}$ of input/output pairs to find the parameters $\theta$. A different set of input/output pairs that are not included in $T$ is used to evaluate an ANN precision.

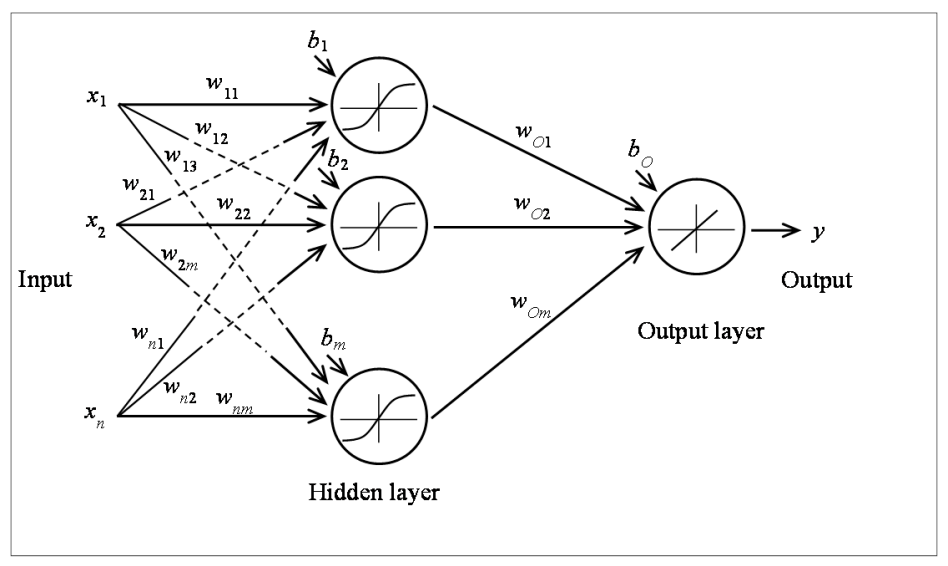

Figure 1. Structure of the feedforward artificial neural network.

Factors (controllable variables $X$ ) affecting the dimensional deviation and surface roughness (output variables $y$ ), according to $[33,38,45]$, are listed in Table 1.

Table 1. Factors affecting surface profile, dimensional deviation, and roughness.

\begin{tabular}{cr}
\hline Classification & Factors \\
\hline Cutting parameters & Cutting speed, depth of cut, feed rate, process kinematics \\
\hline Tool properties & $\begin{array}{c}\text { Tool wear, tool angle, tool nose radius, tool shape, tool material, run-out } \\
\text { errors, tool deflection }\end{array}$ \\
\hline Workpiece properties & Workpiece diameter, length, defect in the material \\
\hline Workpiece material & $\begin{array}{c}\text { Chemical composition, mechanical properties: hardness, tensile and } \\
\text { yield strength, elongation and reduction in area, toughness, creep } \\
\text { resistance, fatigue resistance }\end{array}$ \\
\hline Machining equipment & $\begin{array}{c}\text { Chatter, vibrations, noise, cutting forces } \\
\text { Machining environment }\end{array}$ \\
\hline
\end{tabular}

Among these factors, according to [33,38,39], cutting speed, depth of cut, and feed rate are most often used to determine the influence on the quality of a produced surface. These factors were used in the prediction models discussed later. The authors in [29,33-41,43-45] use prediction models for dimensional deviation and surface roughness prediction only. They do not deal with the integration of models into the process of quality control.

The critical survey in Sections 2.1-2.3 implies that intelligent technologies are not fully integrated into traditional methods of Lean Six Sigma and process quality control. Therefore, our research is going to address this issue to further move industrial processes towards business sustainability.

\section{Methods and Materials}

The new, innovative Lean Six Sigma Small Mixed Batch (LSS-SMB) method was developed by making use of the ANN and machine learning approach in addition to the standard set of LSS tools. This method was applied in the bakery machine manufacturer organization for improvement of the turning process. The following Sections describe the problem that needed to be solved and explain the new LSS-SMB method and its implementation. 


\subsection{Organization and Problem Description}

The research was conducted in an organization that develops innovative solutions for the bakery industry. A medium-sized, engineering-oriented organization with a small production volume has a diverse range of product-mix and many machine settings for different production orders. The main end products are bakery machines. The machines are made up of components like conveyors, hoppers, cylinders, and electrical cabinets. The assembly of these components creates units for processing a bakery dough, forming and molding units, and food ingredient-dispensing units. Almost every project has specific customer requirements and is a so-called "turn-key" solution. Therefore, manufacturing can be considered as SMB production.

Stainless-steel cylinders are one of the most important and expensive components of produced units. Each cylinder consists of a tube (A), a side flange (B), and a shaft (C) (Table 2). Product volume is about 1800 pcs/year in 271 design variants. The cylinder material AISI 304 (X5CrNi18-10) DIN 1.4301 or AISI 304L (X2CrNi18 9) DIN 1.4307 is purchased from European (EUR) and Indian (IND) suppliers. Cylinders are machined by turning on CNC center MAZAK QTN 350, and the cylinder type determines the lathe machine set-up. The resulting CTQ characteristic is a shaft precise diameter $\varnothing 50 h 6$ obtained from stainless steel rod $\varnothing 80 h 9$ by hard and finish turning. For finish turning, a coated cemented carbide cutting tool (CVD TICN+AL2O3+TIN), manufactured by Sandvik, Sweden, is used. The new cutting tool is used for each workpiece.

Table 2. Basic components, material, and critical to quality (CTQ) characteristics of the cylinder.

\begin{tabular}{|c|c|c|c|c|}
\hline \multirow{2}{*}{ Type } & \multirow{2}{*}{$\begin{array}{l}\text { Cylinder and Its } \\
\text { Components * }\end{array}$} & \multirow{2}{*}{ Material } & \multicolumn{2}{|c|}{ CTQ Specification } \\
\hline & & & Precise Diameter & Roughness Ra \\
\hline 400 & \multirow{3}{*}{${ }^{B}{ }^{A}$} & \multirow{3}{*}{$\begin{array}{c}\text { AISI } 304 \text { DIN1.4301 } \\
\text { AISI 304L DIN } \\
1.4307\end{array}$} & \multirow{3}{*}{$\varnothing 50_{-0.019}^{+0.000} \mathrm{~mm}$} & \multirow{3}{*}{$1.1 \mu \mathrm{m}$} \\
\hline 600 & & & & \\
\hline 800 & & & & \\
\hline
\end{tabular}

One of the most important problems of the organization was the cylinder scrap rate of about $14 \%$. The Pareto analysis showed that the main cause of non-conformity was the exceeding of precise diameter and roughness specifications. Therefore, the improvement was focused on the turning process. The organization decided to implement the Six Sigma project, where the data-driven quality strategy is used. The precise diameter $\varnothing 50 h 6$ and roughness Ra is measured after completion of a batch of three cylinders (type 400, type 600, type 800 ) loaded into pallets and transferred to the quality inspection with an average time lapse up to $12 \mathrm{~h}$.

The problem was investigated in detail using the 8D report (Appendix A Table A1). Part D3 of the $8 \mathrm{D}$ report highlights the risk of the existence of a similar problem on other cylinders in the batch. Therefore, the innovative Lean Six Sigma Small Mixed Batch was designed to improve the production system.

\subsection{Lean Six Sigma Small Mixed Batch Method}

The essence of the LSS-SMB method lies in the use of Define-Measure-Analyze-Improve-Control (DMAIC) phases in repetitive cycles until the expected improvement of the process under investigation is achieved. The method takes into account the specifics of the short-run and small mixed batch production system. It uses several tools from the well-known Lean Six Sigma toolbox that was extended by artificial neural networks (ANN) and machine learning. Figure 2 shows the DMAIC phases, activities, and selected tools of the LSS-SMB method. 


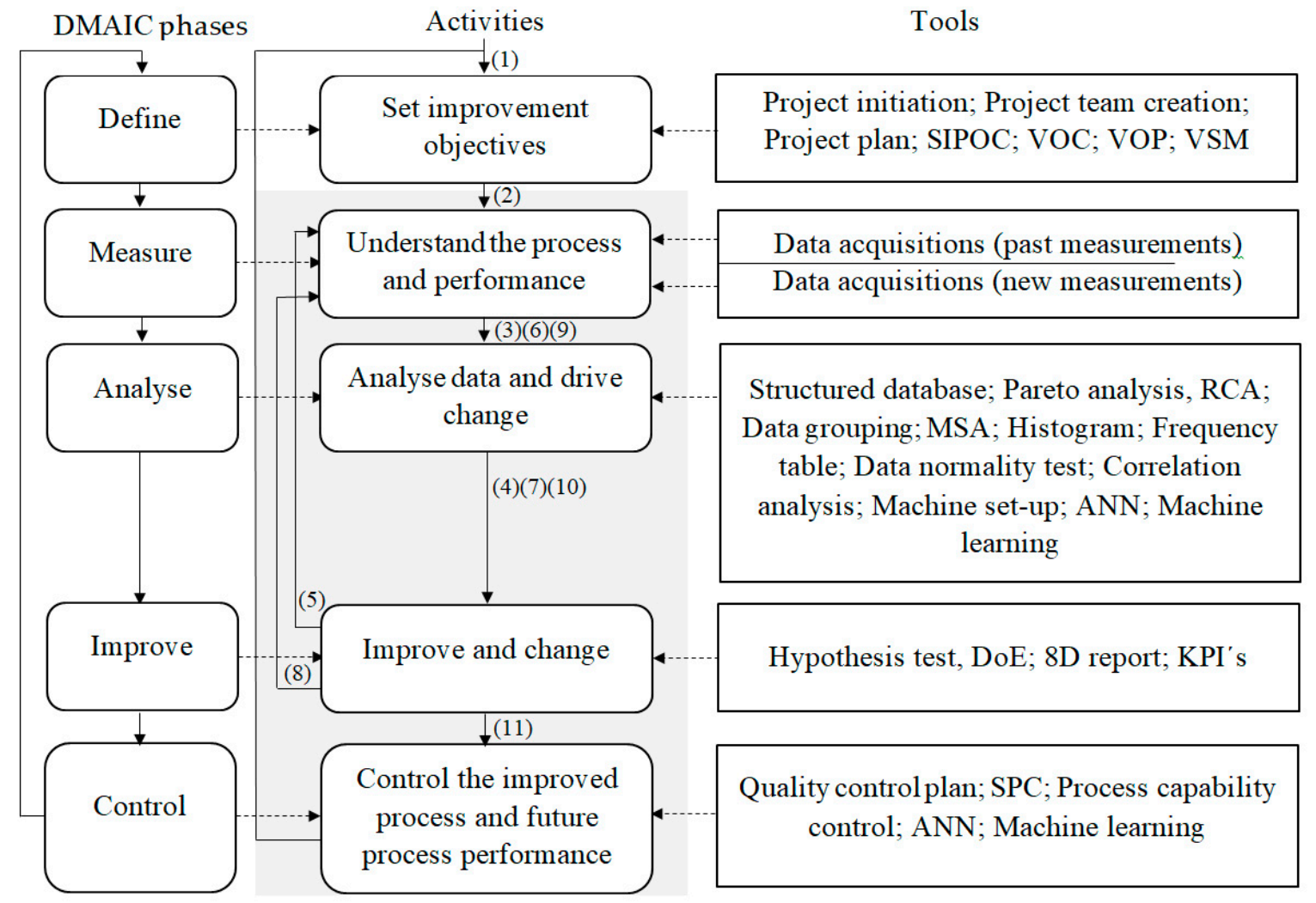

Figure 2. Lean Six Sigma Small Mixed Batch production system method. Legend: SIPOC—acronym for Suppliers, Inputs, Process, Outputs, and Customers; VOC—voice of customer; VOP—voice of process; VSM — value stream mapping; RCA—root cause analysis; MSA —-measurement system analysis; 8D—eight disciplines problem-solving method; KPI—-key performance indicators; SPC —statistical process control; $\mathrm{Cp}, \mathrm{Cpk}$ - process capability index; $\mathrm{Pp}, \mathrm{Ppk}$ - process performance index.

The method is implemented using a sequence of the following steps:

(1)-Improvement objectives are set in the Define phase of the DMAIC cycle.

(2) -Existing data are collected and processed in the Measure phase of the DMAIC cycle.

(3) - The collected data from the past measurements are analyzed with appropriate tools, and the necessary changes are determined in the Analysis phase.

(4) - The changes are realized in the Improvement phase using suitable tools.

(5)-If necessary, new measurements are designed and performed in the next cycle through the Measurement phase.

(6) - New measurements are analyzed to determine if further changes are needed.

(7) - Further changes are realized in the repeated Improvement phase of the DMAIC cycle using suitable tools.

(8-10) - The phases Measure, Analyze, and Improve are repeated until the improvement objectives are reached.

(11) - The process is maintained in the improved condition through a better understanding of the process obtained in the preceding steps.

\subsection{Data Collection}

In the first stage of the project (beginning of the 2018), 150 individually measured data for one design variant recorded on paper forms were transferred to table (Appendix B Table A2). The data represents the deviation from the precise diameter of $\varnothing 50 \mathrm{~mm}$. The initial target value of deviation $(T)$ was set by the operator to $-0.008 \mathrm{~mm}$. 
In the second stage of the project in 2018, Lean Six Sigma training was conducted for project team members and operators. The high-speed optical micrometer was purchased, and data was directly recorded into the Excel table (Appendix B Table A3). Measured data were separated according to EUR supplier (100 records) and IND supplier (100 records) for all design variants.

The third stage of the project in 2019 brought a detailed recording of input material properties: diameter deviation, roughness, chemical composition, and mechanical properties, from individual inspection certificates. Twenty-six records are intended for the prediction models calculation (Appendix B Table A4).

\subsection{Data Analysis}

The analysis of measurements from the year 2017 shows missing data between 0.000 and $-0.010 \mathrm{~mm}$ in the histogram (Figure 3a). The run chart in Figure 3b displays dependence of variance and mean value on the workpiece material supplier. It was concluded that the operator and the measuring device influence measured data significantly. Therefore, no deeper data analysis was conducted for these measurements.
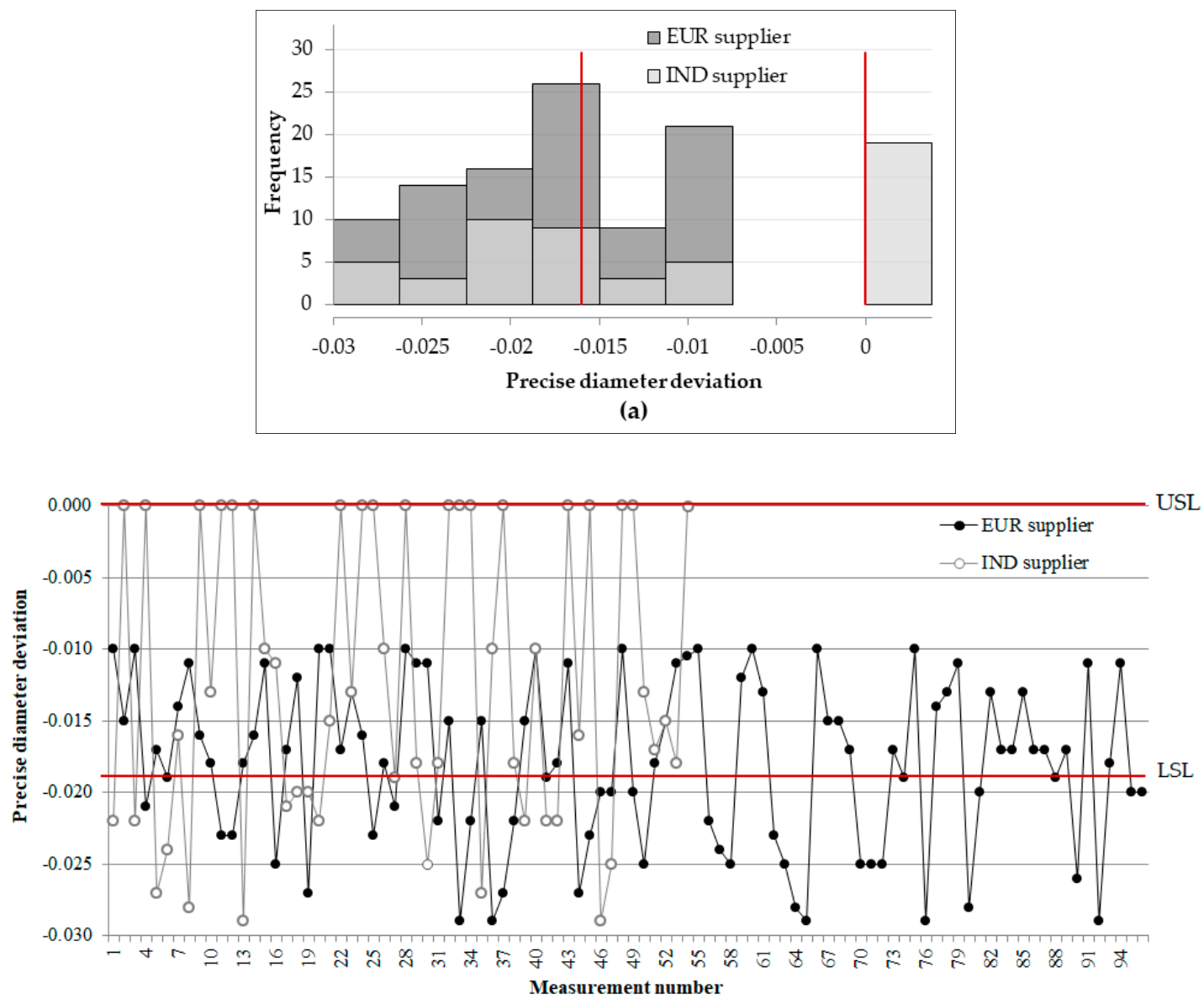

(b)

Figure 3. Measured data recorded by European (EUR) and Indian (IND) material supplier (a) histogram; (b) the run chart for precise diameter deviation (data from the year 2017).

Based on process expert recommendation, the depth of cut and finish allowance was changed for EUR material and the machine target value was moved from $-0.008 \mathrm{~mm}$ to $0.000 \mathrm{~mm}$. Input material was labelled with a QR-code according to its origin (EUR or IND). The new lathe machine set-up parameters are listed in Table 3. 
Table 3. Lathe machine set-up parameters.

\begin{tabular}{|c|c|c|c|c|c|c|c|}
\hline \multirow[t]{3}{*}{ Supplier } & \multicolumn{7}{|c|}{ Lathe Machine Set-Up Parameters } \\
\hline & \multicolumn{2}{|c|}{ Cutting Speed $\left(\mathrm{v}_{\mathrm{c}}\right)[\mathrm{m} / \mathrm{min}]$} & \multicolumn{2}{|c|}{ Depth of Cut $\left(a_{p}\right)[\mathrm{mm}]$} & \multicolumn{2}{|c|}{ Feed Rate (f) $[\mathrm{mm} / \mathrm{rev}]$} & \multirow{2}{*}{$\begin{array}{c}\text { Allowance }[\mathrm{mm}] \\
\text { Roughing }\end{array}$} \\
\hline & Roughing & Finishing & Roughing & Finishing & Roughing & Finishing & \\
\hline EUR & 180 & 110 & $2.0\left(2.5^{1}\right)$ & $1.0\left(0.5^{1}\right)$ & 0.25 & 0.2 & $1.0\left(0.5^{1}\right)$ \\
\hline IND & 180 & 110 & 2.0 & 1.0 & 0.25 & 0.2 & 1.0 \\
\hline
\end{tabular}

The analysis of measurements from the year 2018 showed that data are normally distributed, the process capability is 0.94 for EUR supplier, and 0.73 for IND supplier, but the target $C p k=1.33$ was not met. Therefore, a more in-depth analysis was required to find out the cause of variability. Dimensional deviation and roughness are influenced not only by machine set-up but also depend on material properties. New analysis should consider different sub-suppliers and material properties according to the inspection certificate. Histogram and individual moving range (IMR) charts are shown in Figure 4.

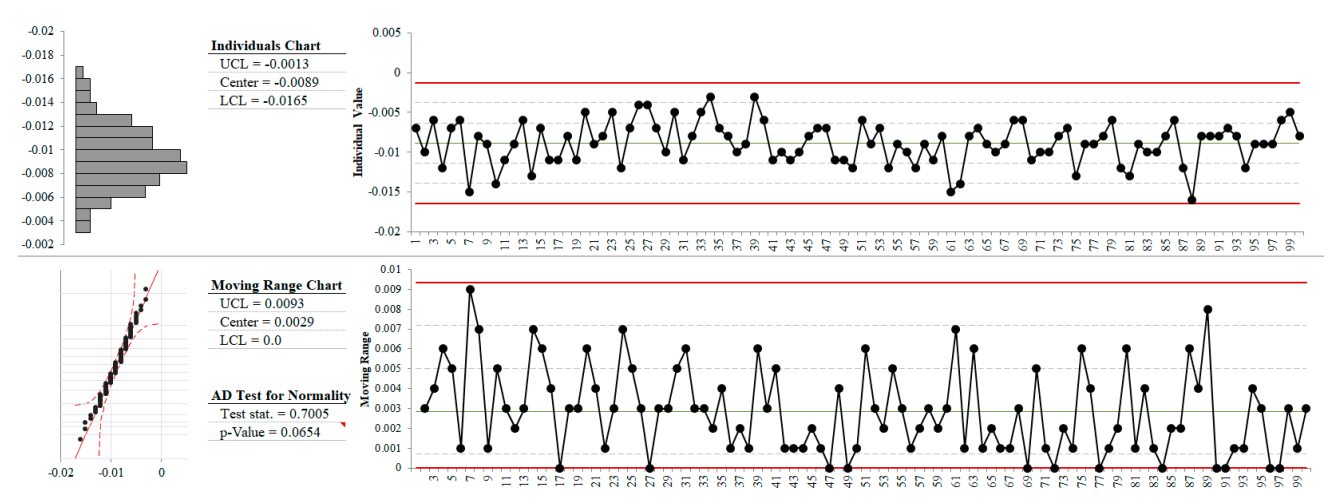

(a)
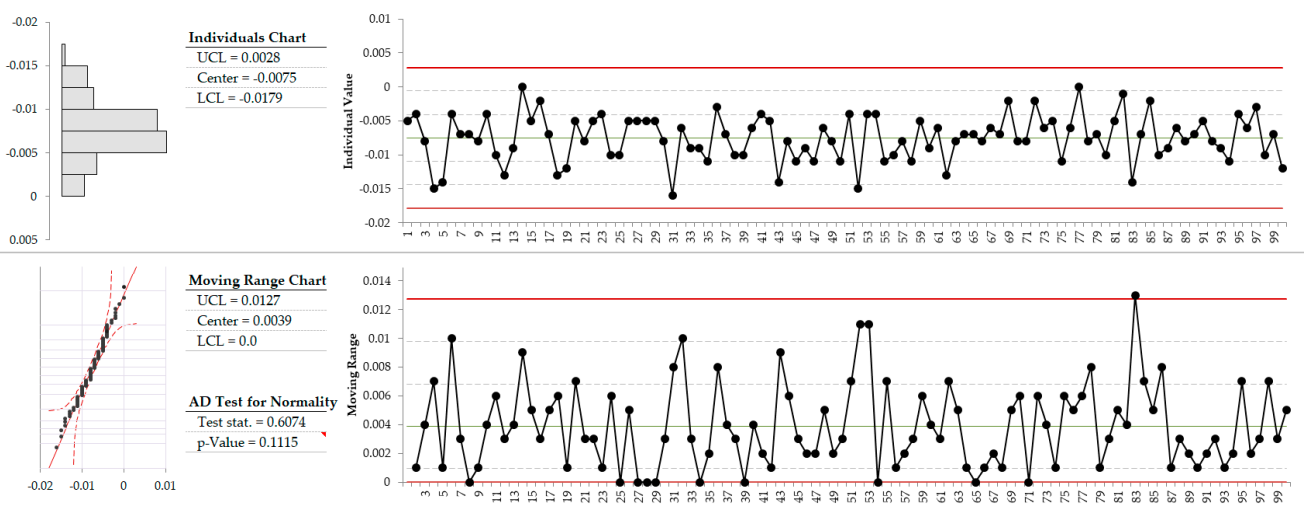

(b)

Figure 4. Histogram and individual moving range charts for diameter deviation: (a) EUR suppliers, (b) IND suppliers (data from the year 2018).

The analysis of measurements from the year 2019 showed that even the chemical composition, mechanical properties, and hardness of the material are within tolerances; they influence the investigated CTQ characteristics. Table 4 shows an observed range of material properties and CTQ characteristics of the cylinder after finish turning. 
Table 4. Range of the chemical and mechanical properties, precise diameter deviations and roughness $\mathrm{Ra}$ (data from the year 2019).

\begin{tabular}{|c|c|c|c|c|}
\hline Material & Chemical Composition [\%] & Mechanical Properties & Roughness Ra & Diameter Deviation \\
\hline EUR supplier & $\begin{array}{c}0.012-0.026 \% \mathrm{C} \\
0.260-0.500 \% \mathrm{Si} \\
1.510-1.850 \% \mathrm{Mn} \\
0.036-0.040 \% \mathrm{P} \\
0.015-0.030 \% \mathrm{~S} \\
18.041-18.200 \% \mathrm{Cr} \\
8.020-8.130 \% \mathrm{Ni}\end{array}$ & $\begin{array}{c}\text { H: } 167-170 \mathrm{HBW} \\
\text { YS(Rp0.2): } 235-318 \mathrm{MPa} \\
\text { A: } 53.2-58 \%\end{array}$ & 0.832 to 1.002 & -0.001 to -0.006 \\
\hline IND supplier & $\begin{array}{c}0.017-0.027 \% \mathrm{C} \\
0.260-0.490 \% \mathrm{Si} \\
1.450-1.800 \% \mathrm{Mn} \\
0.036-0.042 \% \mathrm{P} \\
0.018-0.025 \% \mathrm{~S} \\
18.030-18.370 \% \mathrm{Cr} \\
8.020-8.280 \% \mathrm{Ni}\end{array}$ & $\begin{array}{c}\text { H: } 158-176 \mathrm{HBW} \\
\text { YS (Rp0.2): } 192-270 \mathrm{MPa} \\
\text { A: } 53-73 \%\end{array}$ & 0.802 to 0.990 & 0.000 to -0.012 \\
\hline
\end{tabular}

Legend: H-Hardness [HBW]; YS (Rp0.2)—Yield strength [MPa]; A-Elongation [\%].

Therefore, the collected data were used to create two models to estimate the diameter deviation and two models for roughness Ra estimation after turning operation, based on the knowledge of the material properties of stainless steel used. Both models have three input variables: yield strength RP0.2, elongation, and hardness. The first of the two models uses the response surface method (RSM) and the second-order polynomial model described by Equation (1).

The second model uses feedforward ANN, as described in Section 2.3. The network has one hidden layer with ten neurons with a hyperbolic tangent sigmoid activation function. The output layer has one neuron with a linear activation function. The models were created in Matlab software (Total Academic Headcount license).

Table 5 shows the values of the Coefficient of Determination $R^{2}$ used to assess how good the model is. The value closer to one is better. Training of ANN is a stochastic process. Therefore, 30 independent runs were statistically evaluated to compare three different training methods. Appendix B Table A5 contains results for three to ten neurons in the hidden layer. The ANN trained with Levenberg-Marquardt backpropagation algorithm with ten neurons in the hidden layer has higher value of $\mathrm{R}^{2}$ at shorter calculation time.

Table 5. Comparison of prediction models (30 runs for statistical evaluation of artificial neural networks with ten neurons in hidden layer).

\begin{tabular}{|c|c|c|c|c|c|c|c|c|}
\hline & & Prediction Model & Coeffic & f Deter & ation $R^{2}$ & Calc & n Time & hutes] \\
\hline \multirow{5}{*}{$\begin{array}{l}\text { Diameter } \\
\text { deviation }\end{array}$} & \multirow{4}{*}{ ANN } & Training Method & Max & Min & Mean & Max & Min & Mean \\
\hline & & Levenberg-Marquardt & 0.990 & 0.986 & 0.946 & 2.00 & 1.59 & 1.41 \\
\hline & & Scaled Conjugate Gradient & 0.974 & 0.972 & 0.953 & 3.13 & 2.09 & 1.52 \\
\hline & & BFGS Quasi-Newton & 0.978 & 0.969 & 0.890 & 6.16 & 4.28 & 3.00 \\
\hline & \multicolumn{2}{|c|}{ Polynomial regression } & & 0.917 & & & $<0.1$ & \\
\hline \multirow{5}{*}{ Roughness Ra } & \multirow{4}{*}{ ANN } & Training Method & Max & Min & Mean & Max & Min & Mean \\
\hline & & Levenberg-Marquardt & 0.973 & 0.876 & 0.966 & 4.75 & 1.51 & 2.35 \\
\hline & & Scaled Conjugate Gradient & 0.973 & 0.948 & 0.964 & 9.24 & 6.36 & 8.06 \\
\hline & & BFGS Quasi-Newton & 0.974 & 0.724 & 0.950 & 11.9 & 6.66 & 9.69 \\
\hline & \multicolumn{2}{|c|}{ Polynomial regression } & & 0.892 & & & $<0.1$ & \\
\hline
\end{tabular}

A comparison of the diameter deviation model's accuracy is graphically presented in Figure $5 \mathrm{a}$. The models use 23 samples from 26 because the preliminary calculation revealed three outliers. Two randomly chosen samples, No 5 (material supplier from IND) and No 18 (EUR supplier), were excluded from the model calculation to demonstrate model accuracy and behavior for the input that is outside of the set of known samples. Similarly, the comparison of the accuracy of roughness Ra models is depicted in Figure 5b. From Figure 5a,b it is evident that: 
- The functional dependence between steel mechanical properties and monitored CTQ characteristics exists, and an appropriate model can be created to predict values of diameter deviation and roughness after machining.

- Models can predict values outside of the set of known samples with lower but sufficient precision.

- The accuracy of the ANN model is better than the polynomial regression model in both cases.
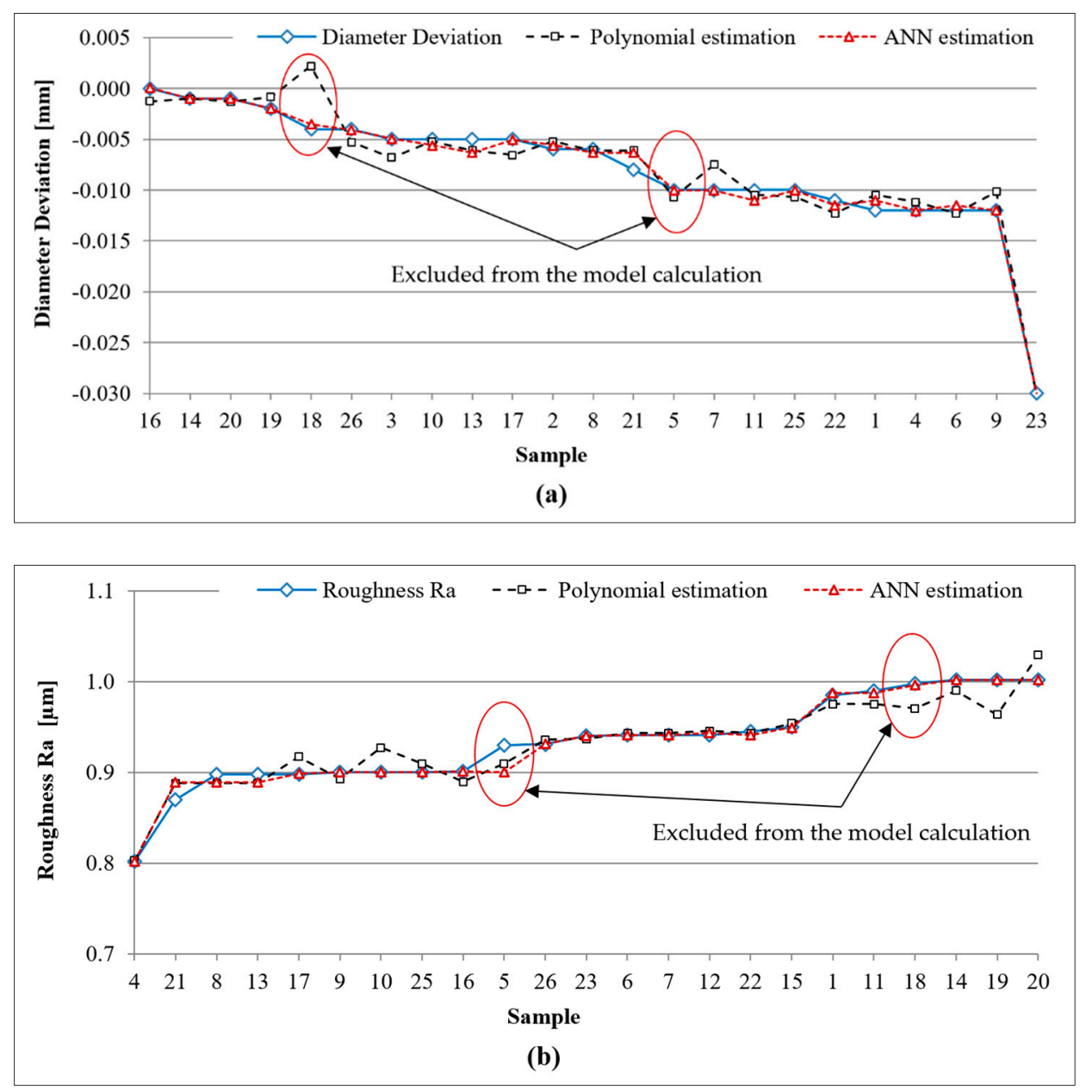

Figure 5. Comparison of the actual and estimated values of (a) diameter deviation, (b) roughness Ra.

The presented models can be used for prediction of the diameter deviation and roughness if a new supplier or new steel grade will appear.

\section{Results}

In this section, the results of the newly developed LSS-SMB method applied on the turning process are described. The application of the method brought an incremental improvement during the years 2018 and 2019. The proposed method is a sequence of quality improvement steps based on Lean Six Sigma DMAIC. Therefore, the results are described in chronological order.

The LSS-SMB project started in 2018 by analyzing historical data from 2017. The analysis revealed problems due to inaccurate measurement and recording of data by the operator. At the same time, it showed an improper lathe machine set-up and that the material from different suppliers (EUR or IND) significantly affects the CTQ characteristics. The following steps were taken as part of the improvement: the operator was trained for Lean Six Sigma, the measuring instrument was replaced, and the lathe machine set-up changed according to the material supplier. 
Table 6 summarizes the results of the first project stage. It contains the tools and the results of the use of those tools for each step numbered according to Figure 2. For example, in the LSS phase (1) Define, the Project initiation tool was used, and the result is a Project charter. The LSS phase (3) Analyze also includes Findings, which identify the cause of the problem. This structure is repeated in Tables 7 and 8.

Table 6. The project's gradual results from the 1st project stage.

\begin{tabular}{|c|c|c|}
\hline LSS Phase & Tools & Results and Findings \\
\hline (1) Define & $\begin{array}{ll}\text { - } & \text { Project initiation } \\
\text { - } & \text { Project team creation } \\
\text { - } & \text { Project plan } \\
\text { - } & \text { Project goal } \\
\text { - } & \text { Gant diagram } \\
\text { - } & \text { SIPOC }\end{array}$ & $\begin{array}{l}\text { Results: } \\
\text { - } \quad \text { Project charter: 2018-2019 } \\
\text { - } \quad \text { Goal: Achieving of the turning process capability Cpk }=1.33 \\
\text { SIPOC definition: } \\
\text { - } \quad \text { Supplier (internal): welding shop } \\
\text { - } \quad \text { Input material: steel rod } \varnothing 80 \mathrm{~h} 9 \\
\text { - } \quad \text { Output: cylinder CTQ characteristics (precise diameter } \\
\quad \varnothing 50 \mathrm{h6} \text { mm, roughness Ra }=1.1 \mu \mathrm{m}) \\
\text { - } \quad \text { Customer (internal): assembling department }\end{array}$ \\
\hline (2) Measure (Data from the year 2017) & $\begin{array}{l}\text { Data acquisition } \\
\text { Database } \\
\text { Data grouping } \\
\text { MSA }\end{array}$ & $\begin{array}{l}\text { Results: } \\
\text { - } \quad \text { Electronic database of past measurements } \\
\text { - Data grouped by material origin (EUR, IND) as they had the same: } \\
\text { - } \quad \text { machine: CNC turning center MAZAK QTN } 350 \\
\text { - } \quad \text { process: turning (hard; finish) } \\
\text { - CTQ characteristics specification }(\varnothing 50 \mathrm{~h} 6 \mathrm{~mm} \text {; Ra } \leq 1.1 \mu \mathrm{m} \text { ) } \\
\text { - } \quad \text { measuring instrument: digital micrometer (range } 25-50 \mathrm{~mm} \text {; } \\
\text { reading error } 0.005 \mathrm{~mm}) \\
\text { MSA was not conducted }\end{array}$ \\
\hline (3) Analyze (Data from the year 2017) & $\begin{array}{l}\text { Root causes analysis } \\
\text { VOC } \\
\text { Pareto analysis } \\
\text { CTQFrequency analysis } \\
\text { Set-up analysis } \\
\text { Run chart } \\
\text { Capability analysis }\end{array}$ & $\begin{array}{l}\text { Results: } \\
\text { - The total number of non-conformities caused by non-compliance } \\
\text { of precise diameter } \varnothing 50 \mathrm{~h} 6 \mathrm{~mm} \text { is } 8 \% \text {. } \\
\text { - } \quad \text { Frequency analysis: missing data between } 0.000 \text { and }-0.010 \text {. } \\
\text { - Machine set-up analysis: same set-up for }(400,600,800 \text { cylinder } \\
\text { types) (Table } 3 \text { ) } \\
\text { - Histogram, IMR chart, Figure } 3 a, b \\
\text { Findings: } \\
\text { - Initial material inspection is not performed } \\
\text { - } \quad \text { Data rounding by operators } \\
\text { - Insufficient measuring range of measuring device } \\
\text { - The average value of the deviation of precise diameter } \varnothing 50 \text { is } \\
\text { shifted from the target value due to the inappropriate lathe } \\
\text { machine setting. The deviation average is }-0.017 \text { for EUR material, } \\
\text { and, for IND material, it is }-0.015\end{array}$ \\
\hline (4) Improve & $8 \mathrm{D}$ report & $\begin{array}{l}\text { Results: } \\
\text { - } \quad \text { Personnel training for LSS } \\
\text { - } \quad \text { Input material labeling by QR-code } \\
\text { - Changing the lathe machine set-up (Table 3) for hard turning and } \\
\text { - } \quad \text { Pinish turning } \\
\quad \text { optical micrometer }\end{array}$ \\
\hline
\end{tabular}

The analysis of data gathered during the year 2018 showed an improvement in the preliminary process capability, but the organization's stated goal $C p k=1.33$ was still not achieved. Dimensional deviation and roughness variances could not be explained only by machine set-up, or EUR and IND supplier. From this knowledge, the hypothesis arises that the variances are caused by differences in chemical composition and in mechanical properties of the material from individual sub-suppliers. Table 7 summarizes the results of this project stage.

As a part of the next project stage, a more sophisticated analysis of the measured data from 2019 was carried out using analytical modeling and ANN. The result was two models, which confirmed our hypothesis that the variability of CTQ characteristics could be predicted according to the mechanical properties of the input material. This prediction has proved to be very important for further reduction 
in variability and improvement of the turning process capability. This finding leads to the design of the new control scheme (Figure 6).

The created prediction model is used in cooperation with machine learning algorithms to indicate conditions when the change of machine set-up parameters (cutting speed, depth of cut, and feed rate) must compensate for the variation in the mechanical properties of the input material. If predicted characteristics are not within tolerances, then the machine set-up has to be changed. The prediction model allows us to compensate for the variability in supplied steel material properties, which can bring the process under control. A new machine set-up, together with measured inputs, must be recorded. Data will be used to extend existing models in such a way that cutting speed, depth of cut, and feed rate will be included in the set of model inputs. The prediction model will learn from each new measurement by the appropriate machine learning algorithm. A detailed description of the actual project stage results is given in Table 8.

Table 7. The project's gradual results from the 2nd project stage (year 2018).

\begin{tabular}{|c|c|c|}
\hline LSS Phase & Tools & Results and Findings \\
\hline (5) Measure & $\begin{array}{l}\text { Data acquisition } \\
\text { Database } \\
\text { Data grouping } \\
\text { MSA } \\
\text { Capability analysis }\end{array}$ & $\begin{array}{l}\text { Results: } \\
\text { - } \quad \text { Data grouped by material origin (EUR, IND) } \\
\text { - } \quad \text { Electronic data capture from high-speed optical } \\
\text { micrometer to a structured database } \\
\text { - } \quad \text { MSA }(\mathrm{TV}<10 \%)\end{array}$ \\
\hline (6) Analyze & Root causes analysis $8 \mathrm{D}$ report & $\begin{array}{l}\text { Results: } \\
\text { - } \quad \text { Data normality analysis (Shapiro-Wilk test): } \\
\text { normal distribution } \\
\text { - } \quad \text { Correlation analysis: data are not correlated } \\
\text { - } \quad \text { Histogram and IMR charts Figure 4a EUR supplier; } \\
\text { Figure } 4 \mathrm{~b} \text { IND supplier } \\
\text { - } \quad \text { Preliminary process capability for EUR supplier } \\
\quad \text { Cpk }=0.94 \text { and IND supplier Cpk }=0.73 \\
\text { Results: } \\
\text { - Hypothesis: Variances in chemical composition and } \\
\quad \text { mechanical properties of the material from individual } \\
\text { - } \quad \text { Fub-suppliers are significant } \\
\text { non-conformity causes }\end{array}$ \\
\hline (7) Improve & $8 \mathrm{D}$ report & $\begin{array}{l}\text { Results: } \\
\text { - Extended recording of the mechanical properties of the } \\
\text { input material }\end{array}$ \\
\hline
\end{tabular}

Legend: LSS—Lean Six Sigma; MSA—-measurement system analysis; EUR—Europe; IND—India; IMR—individual moving range; $\mathrm{Cpk}$ - process capability.

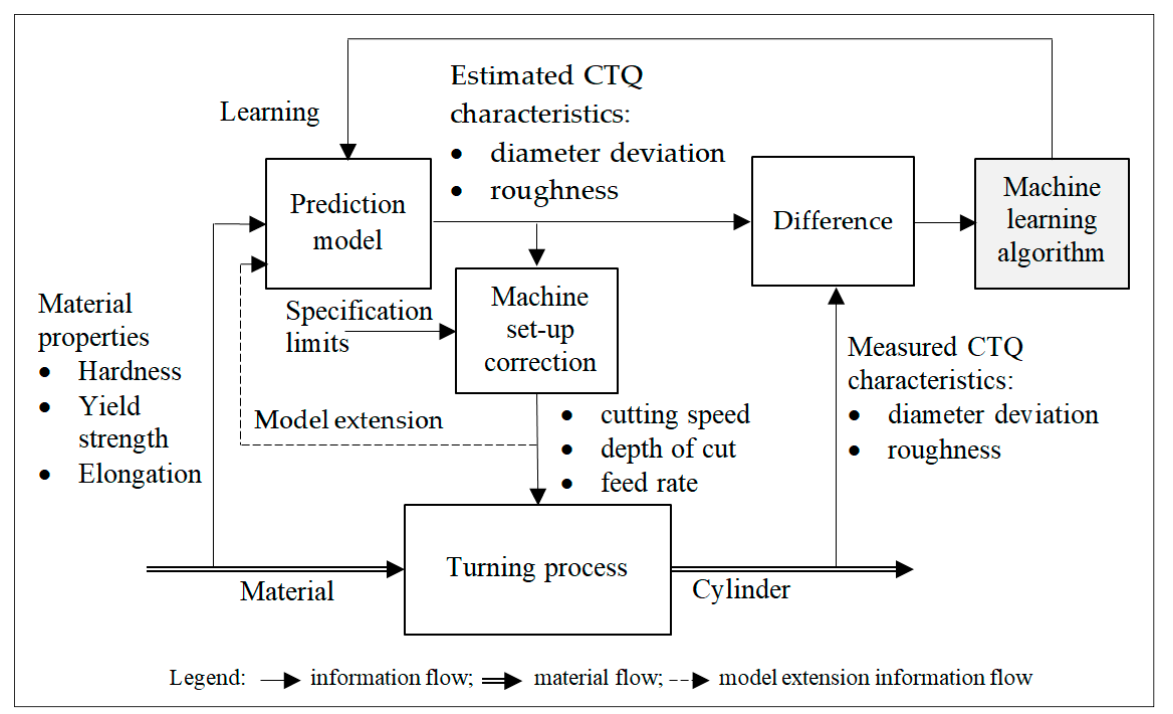

Figure 6. Control scheme using the prediction model to reduce variability in process outputs. 
Table 8. Project gradual results from the 3rd project stage (year 2019).

\begin{tabular}{|c|c|c|}
\hline LSS Phase & Tools & Results and Findings \\
\hline (8) Measure & Capability analysis & $\begin{array}{l}\text { Results: } \\
\text { - } \quad \text { New data measurement and gathering material } \\
\text { properties from the inspection certificates }\end{array}$ \\
\hline (9) Analyze & $\begin{array}{l}\text { Predictive modeling } \\
\text { Root causes analysis }\end{array}$ & $\begin{array}{l}\text { Result: } \\
\text { - Second-order polynomial models and ANN } \\
\text { models to estimate the diameter deviation and } \\
\text { roughness Ra } \\
\text { Findings: } \\
\text { - The hypothesis that variances in mechanical } \\
\text { properties of the material from individual } \\
\text { sub-suppliers are significant is confirmed. } \\
\text { The model can predict the precise diameter } \\
\text { deviation and roughness. }\end{array}$ \\
\hline (10) Improve & $8 \mathrm{D}$ report & $\begin{array}{l}\text { Results: } \\
\text { - } \quad \text { Design of the control scheme for reducing } \\
\text { variability in process outputs (Figure 6) }\end{array}$ \\
\hline $\begin{array}{c}\text { (11) Control } \\
\text { (Not realized yet) }\end{array}$ & $\begin{array}{l}\text { Quality control plan } \\
\text { SPC }\end{array}$ & $\begin{array}{l}\text { Result: } \\
\text { - Keeping the process in an improved state using } \\
\text { the practices outlined in the QC plan and SPC. }\end{array}$ \\
\hline
\end{tabular}

Legend: LSS—Lean Six Sigma; SPC—statistical process control; QC—quality control.

\section{Discussion}

The current state of knowledge presented in the literature [22-26] shows that the tools of intelligent technologies $[27,28]$ are not fully integrated into the traditional methods of Lean Six Sigma DMAIC and process quality control and real-time data availability is not currently used. Therefore, we extended the traditional method with ANN tools, machine learning, and predictive models in the Analysis and Control phases, according to Figure 2. We added an internal cycle in the DMAIC where the Measurement-Analysis-Improvement phases are repeated to make full use of real-time data.

The literature $[11,30]$ describes the concept of intelligent SPC that uses gathered data, artificial neural networks, and machine learning to improve the automatic detection of the out of control state of the process [31,32]. This approach indicates only the already existing shift of the process, and it does not compensate for the input variability.

The application of the new LSS-SMB in a bakery machine manufacturer has shown us that the tools used so far are not enough to reduce the variability of the turning process. A more in-depth analysis revealed that information from inspection certificates could be used to predict the observed CTQ characteristics and allows the operator to change the process set-up parameters in advance. It has therefore proved appropriate to incorporate intelligent technologies into the LSS-SMB method and to use previously unused information and thus improve the logistics of the flow of information obtained from suppliers' material certificates.

Predictive models for dimensional deviation and surface roughness have already been created, but the authors $[29,37-45]$ did not integrate them into the process quality control. Our proposed control scheme (Figure 6) responds to changes in material properties and corrects the process in advance (feedforward control). The whole system learns and improves automatically through machine learning.

The presented case study confirmed the functionality and applicability of the proposed LSS-SMB method in the case of a bakery machine producer. Its application led to the proposal to improve the entire process control system, which uses intelligent technologies for further reduction in variability and process capability improvement. 
The limitation of the LSS-SMB method is that the prediction models are based on data from the past, and the real future may be different. Therefore, intelligent SPC will also have to be used. The diagram in Figure 6 is incomplete because it does not directly determine the lathe machine set-up. In future research, we would like to:

- Analyze whether the prediction model, which includes a larger number of samples and, at the same time, takes into account the chemical composition of the material, will be more accurate.

- Modify the control scheme to determine the machine set-up correction directly.

- Determine how the LSS-SMB application contributed to the bakery machine manufacturer's business sustainability.

The organization will benefit from the proposed LSS-SMB if the presented control scheme is implemented.

\section{Conclusions}

The paper has presented the innovative Lean Six Sigma methodology for Small Mixed Batch production systems. The standard set of LSS tools is extended by intelligent technologies, namely artificial neural networks and machine learning. The LSS-SMB methodology is illustrated in the case study of the bakery machine turning process. The step-by-step DMAIC procedure was conducted with the following results:

- Data analysis revealed that operators inaccurately recorded measurement data, and the measuring device did not have a sufficient range. Therefore the measurement instrument was changed, and operators were trained on how to use it.

- The average value of the deviation of precise diameter is shifted from the target value; therefore, lathe machine set-up was corrected.

- Further analysis of data shown that the variance of mechanical properties of the material from the same suppliers influences the precise diameter deviation and roughness. Therefore, the advanced mathematical model based on ANN that allows prediction of CTQ characteristics from input material properties was built. The created prediction model is a part of a newly designed process variability control scheme using machine learning algorithms to reduce the variability for input material with different properties from new suppliers.

As further causes of variability have been identified, and the process has become statistically stable, it is possible to proceed with the implementation of SPC for SMB production. Acquired experiences will be used by the organization to improve other organization processes. The use of modern advanced methods such as mathematical modeling, ANN, and machine learning is a necessary step in further quality problem-solving in the industry. Therefore, our future research will be focused on the implementation and validation of proposed methods in the context of LSS.

Author Contributions: Conceptualization, K.Z.; methodology, D.J., K.Z. and P.B.; validation, K.Z., P.B. and G.S.; formal analysis, D.J. and K.M.; data curation, D.J.; writing-original draft preparation, K.Z. and P.B.; writing-review and editing, K.Z. and V.M.; visualization, D.J.; supervision, K.Z.; project administration, K.Z. and D.J.; funding acquisition, K.Z., P.B. and D.J. All authors have read and agreed to the published version of the manuscript.

Funding: This research was funded by MINISTERSTVO ŠKOLSTVA, VEDY, VÝSKUMU A ŠPORTU SLOVENSKEJ REPUBLIKY, grant number VEGA 1/0187/18 “Development of dynamically demanding and energy-optimal electromechanical systems", and grant number KEGA 043TUKE-4/2019 “Improving material engineering and integrated management systems study programs for Industry $4.0^{\prime \prime}$.

Conflicts of Interest: The authors declare no conflict of interest. The funders had no role in the design of the study; in the collection, analyses, or interpretation of data; in the writing of the manuscript, or in the decision to publish the results. 


\section{Appendix A}

Table A1. 8D report.

\begin{tabular}{|c|c|}
\hline D1 Team formation & LSS-SMB project manager, quality engineer, process engineer, set-up operator, lathe operator. \\
\hline D2 Problem description & $\begin{array}{l}\text { Part number: Roller } \\
\text { 400XXXXXXXXX72 }\end{array}$ \\
\hline What? & $\begin{array}{l}\text { The surface quality and } \\
\text { dimensional deviation Ø50 } \mathrm{h} 6 \text { is } \\
\text { NOK }\end{array}$ \\
\hline Why? & \\
\hline Where? & Unit assembly department \\
\hline When? & Preparation of roller for UNIT assembly \\
\hline Who? & Assembly operator \\
\hline How? & Pre-assembly visual control \\
\hline How many? & One piece \\
\hline Part manufacturing date: & November 29, 2017 \\
\hline Re-occurrence: & Yes \\
\hline D3 Risk on a similar product and process & Yes. Similar rollers produced at the same time: Roller 60000000026 . Roller 80000007242. \\
\hline D4 Root causes of occurrence & After lathe operation, the surface quality of precise roller diameter not controlled. \\
\hline D5 Root causes of non-detection (RCO) & $\begin{array}{l}\text { 1) Lathe operators not instructed to control product surface quality when lathe operation is finished. 2) } \\
\text { Quality control department not instructed to inspect the surface quality and surface damages after } \\
\text { lathe operation. }\end{array}$ \\
\hline D6 Permanent countermeasures & $\begin{array}{l}\text { 1) Inspect surface quality of roller in precise diameter area by the operator and set up product release } \\
\text { by the shift leader. 2) Inspect surface quality of roller by the Quality control department. 3) Lathe } \\
\text { operation instruction updated. 4) Lathe operators trained. 5) Quality control instruction updated. 6) } \\
\text { Quality control department staff trained. }\end{array}$ \\
\hline D7 Effectiveness & $\begin{array}{l}\text { Check effectiveness result during the next } 3 \text { productions (lathe operation of rollers 400-600-800). Verify } \\
\text { roller surface quality after lathe operation. }\end{array}$ \\
\hline D8 Lessons learned & $\begin{array}{l}\text { 1) Verify documents: Lathe instruction; Quality control instruction, 2) Verify samples: Verify three } \\
\text { types of rollers }(400,600,800) \text { prior assembly - after lathe operation, 3) Verify staff: Lathe department, } \\
\text { Quality control department. }\end{array}$ \\
\hline
\end{tabular}

\section{Appendix B}

Table A2. Measurements from the year 2017.

\begin{tabular}{cccccccccccc}
\hline No & EUR & IND & No & EUR & IND & No & EUR & IND & No & EUR & IND \\
\hline 1 & -0.010 & -0.022 & 25 & -0.023 & 0.000 & 49 & -0.020 & 0.000 & 73 & -0.017 & \\
2 & -0.015 & 0.000 & 26 & -0.018 & -0.010 & 50 & -0.025 & -0.013 & 74 & -0.019 & \\
3 & -0.010 & -0.022 & 27 & -0.021 & -0.019 & 51 & -0.018 & -0.017 & 75 & -0.010 & \\
4 & -0.021 & 0.000 & 28 & -0.010 & 0.000 & 52 & -0.015 & -0.015 & 76 & -0.029 & \\
5 & -0.017 & -0.027 & 29 & -0.011 & -0.018 & 53 & -0.011 & -0.018 & 77 & -0.014 & \\
6 & -0.019 & -0.024 & 30 & -0.011 & -0.025 & 54 & -0.011 & 0.000 & 78 & -0.013 & \\
7 & -0.014 & -0.016 & 31 & -0.022 & -0.018 & 55 & -0.010 & & 79 & -0.011 & \\
8 & -0.011 & -0.028 & 32 & -0.015 & 0.000 & 56 & -0.022 & & 80 & -0.028 & \\
9 & -0.016 & 0.000 & 33 & -0.029 & 0.000 & 57 & -0.024 & & 81 & -0.020 & \\
10 & -0.018 & -0.013 & 34 & -0.022 & 0.000 & 58 & -0.025 & & 82 & -0.013 & \\
11 & -0.023 & 0.000 & 35 & -0.015 & -0.027 & 59 & -0.012 & & 83 & -0.017 & \\
12 & -0.023 & 0.000 & 36 & -0.029 & -0.010 & 60 & -0.010 & & 84 & -0.017 & \\
13 & -0.018 & -0.029 & 37 & -0.027 & 0.000 & 61 & -0.013 & & 85 & -0.013 & \\
14 & -0.016 & 0.000 & 38 & -0.022 & -0.018 & 62 & -0.023 & & 86 & -0.017 & \\
15 & -0.011 & -0.010 & 39 & -0.015 & -0.022 & 63 & -0.025 & & 87 & -0.017 & \\
16 & -0.025 & -0.011 & 40 & -0.010 & -0.010 & 64 & -0.028 & & 88 & -0.019 & \\
17 & -0.017 & -0.021 & 41 & -0.019 & -0.022 & 65 & -0.029 & & 89 & -0.017 & \\
18 & -0.012 & -0.020 & 42 & -0.018 & -0.022 & 66 & -0.010 & & 90 & -0.026 & \\
19 & -0.027 & -0.020 & 43 & -0.011 & 0.000 & 67 & -0.015 & & 91 & -0.011 & \\
20 & -0.010 & -0.022 & 44 & -0.027 & -0.016 & 68 & -0.015 & & 92 & -0.029 & \\
21 & -0.010 & -0.015 & 45 & -0.023 & 0.000 & 69 & -0.017 & & 93 & -0.018 & \\
22 & -0.017 & 0.000 & 46 & -0.020 & -0.029 & 70 & -0.025 & & 94 & -0.011 & \\
23 & -0.013 & -0.013 & 47 & -0.020 & -0.025 & 71 & -0.025 & & 95 & -0.020 & \\
24 & -0.016 & 0.000 & 48 & -0.010 & 0.000 & 72 & -0.025 & & 96 & -0.020 & \\
\hline
\end{tabular}


Table A3. Measurements from the year 2018.

\begin{tabular}{cccccccccccc}
\hline No & EUR & IND & No & EUR & IND & No & EUR & IND & No & EUR & IND \\
\hline 1 & -0.007 & -0.005 & 25 & -0.007 & -0.010 & 49 & -0.011 & -0.008 & 73 & -0.008 & -0.006 \\
2 & -0.010 & -0.004 & 26 & -0.004 & -0.005 & 50 & -0.012 & -0.011 & 74 & -0.007 & -0.005 \\
3 & -0.006 & -0.008 & 27 & -0.004 & -0.005 & 51 & -0.006 & -0.004 & 75 & -0.013 & -0.011 \\
4 & -0.012 & -0.015 & 28 & -0.007 & -0.005 & 52 & -0.009 & -0.015 & 76 & -0.009 & -0.006 \\
5 & -0.007 & -0.014 & 29 & -0.010 & -0.005 & 53 & -0.007 & -0.004 & 77 & -0.009 & 0.000 \\
6 & -0.006 & -0.004 & 30 & -0.005 & -0.008 & 54 & -0.012 & -0.004 & 78 & -0.008 & -0.008 \\
7 & -0.015 & -0.007 & 31 & -0.011 & -0.016 & 55 & -0.009 & -0.011 & 79 & -0.006 & -0.007 \\
8 & -0.008 & -0.007 & 32 & -0.008 & -0.006 & 56 & -0.010 & -0.010 & 80 & -0.012 & -0.010 \\
9 & -0.009 & -0.008 & 33 & -0.005 & -0.009 & 57 & -0.012 & -0.008 & 81 & -0.013 & -0.005 \\
10 & -0.014 & -0.004 & 34 & -0.003 & -0.009 & 58 & -0.009 & -0.011 & 82 & -0.009 & -0.001 \\
11 & -0.011 & -0.010 & 35 & -0.007 & -0.011 & 59 & -0.011 & -0.005 & 83 & -0.010 & -0.014 \\
12 & -0.009 & -0.013 & 36 & -0.008 & -0.003 & 60 & -0.008 & -0.009 & 84 & -0.010 & -0.007 \\
13 & -0.006 & -0.009 & 37 & -0.010 & -0.007 & 61 & -0.015 & -0.006 & 85 & -0.008 & -0.002 \\
14 & -0.013 & 0.000 & 38 & -0.009 & -0.010 & 62 & -0.014 & -0.013 & 86 & -0.006 & -0.010 \\
15 & -0.007 & -0.005 & 39 & -0.003 & -0.010 & 63 & -0.008 & -0.008 & 87 & -0.012 & -0.009 \\
16 & -0.011 & -0.002 & 40 & -0.006 & -0.006 & 64 & -0.007 & -0.007 & 88 & -0.016 & -0.006 \\
17 & -0.011 & -0.007 & 41 & -0.011 & -0.004 & 65 & -0.009 & -0.007 & 89 & -0.008 & -0.008 \\
18 & -0.008 & -0.013 & 42 & -0.010 & -0.005 & 66 & -0.010 & -0.008 & 90 & -0.008 & -0.007 \\
19 & -0.011 & -0.012 & 43 & -0.011 & -0.014 & 67 & -0.009 & -0.006 & 91 & -0.008 & -0.005 \\
20 & -0.005 & -0.005 & 44 & -0.010 & -0.008 & 68 & -0.006 & -0.007 & 92 & -0.007 & -0.008 \\
21 & -0.009 & -0.008 & 45 & -0.008 & -0.011 & 69 & -0.006 & -0.002 & 93 & -0.008 & -0.009 \\
22 & -0.008 & -0.005 & 46 & -0.007 & -0.009 & 70 & -0.011 & -0.008 & 94 & -0.012 & -0.011 \\
23 & -0.005 & -0.004 & 47 & -0.007 & -0.011 & 71 & -0.010 & -0.008 & 95 & -0.009 & -0.004 \\
24 & -0.012 & -0.010 & 48 & -0.011 & -0.006 & 72 & -0.010 & -0.002 & 96 & -0.009 & -0.006 \\
\hline
\end{tabular}

Table A4. Measurements from the year 2019.

\begin{tabular}{|c|c|c|c|c|c|c|}
\hline \multirow[t]{2}{*}{ Sample } & \multirow[t]{2}{*}{ Sub-supplier } & \multicolumn{3}{|c|}{ Mechanical Properties } & \multicolumn{2}{|l|}{ Outputs } \\
\hline & & YS 0.2 & Elongation & Hardness & Diameter Deviation & $\mathbf{R a}$ \\
\hline 1 & IND s-s1 & 292 & 58 & 174 & -0.012 & 0.985 \\
\hline 2 & EUR s-s1 & 235 & 55 & 168 & -0.006 & 0.832 \\
\hline 3 & IND s-s2 & 276.05 & 54 & 158 & -0.005 & 0.808 \\
\hline 4 & IND s-s3 & 270.13 & 54 & 156 & -0.012 & 0.802 \\
\hline 5 & IND s-s4 & 292 & 71 & 174 & -0.010 & 0.930 \\
\hline 6 & IND s-s5 & 284 & 72 & 176 & -0.012 & 0.941 \\
\hline 7 & IND s-s6 & 286 & 59 & 176 & -0.010 & 0.941 \\
\hline 8 & IND s-s7 & 290.53 & 53 & 158 & -0.006 & 0.898 \\
\hline 9 & IND s-s8 & 286 & 73 & 175 & -0.012 & 0.900 \\
\hline 10 & EUR s-s2 & 235 & 55 & 168 & -0.005 & 0.900 \\
\hline 11 & IND s-s9 & 292 & 58 & 174 & -0.010 & 0.990 \\
\hline 12 & IND s-s10 & 284 & 59 & 176 & 0.000 & 0.941 \\
\hline 13 & IND s-s11 & 290.53 & 53 & 158 & -0.005 & 0.898 \\
\hline 14 & EUR s-s3 & 239 & 58 & 170 & -0.001 & 1.002 \\
\hline 15 & IND s-s12 & 286 & 58 & 175 & -0.010 & 0.950 \\
\hline 16 & IND s-s13 & 281 & 57 & 176 & 0.000 & 0.901 \\
\hline 17 & IND s-s14 & 286 & 58 & 176 & -0.005 & 0.898 \\
\hline 18 & EUR s-s4 & 277 & 53.9 & 171 & -0.004 & 0.998 \\
\hline 19 & EUR s-s5 & 249 & 53.2 & 167 & -0.002 & 1.002 \\
\hline 20 & EUR s-s6 & 279 & 53.2 & 167 & -0.001 & 1.002 \\
\hline 21 & IND s-s15 & 290.53 & 53 & 158 & -0.008 & 0.870 \\
\hline 22 & IND s-s16 & 284 & 72 & 176 & -0.011 & 0.945 \\
\hline 23 & EUR s-s7 & 318 & 57.5 & 170 & -0.030 & 0.940 \\
\hline 24 & EUR s-s8 & 235 & 55 & 168 & -0.020 & 0.992 \\
\hline 25 & IND s-s17 & 292 & 71 & 174 & -0.010 & 0.900 \\
\hline 26 & EUR s-s9 & 239 & 54 & 167 & -0.004 & 0.931 \\
\hline
\end{tabular}

YS 0.2—yield strength; IND—India; EUR—Europe; s-s—sub-supplier number; Ra—roughness. 
Table A5. Statistical evaluation of ANN; each line contains statistics for 30 runs.

\begin{tabular}{|c|c|c|c|c|c|c|c|c|}
\hline & \multirow[b]{2}{*}{ Neurons } & \multirow[b]{2}{*}{ Training Function } & \multicolumn{3}{|c|}{ Coefficient of Determination $\mathbf{R}^{2}$} & \multicolumn{3}{|c|}{ Calculation Time [minutes] } \\
\hline & & & Max & Min & Mean & Max & Min & Mean \\
\hline \multirow{24}{*}{$\begin{array}{l}\text { Diameter } \\
\text { Deviation }\end{array}$} & 3 & Levenberg-Marquardt & 0.984 & 0.849 & 0.973 & 6.38 & 1.72 & 3.03 \\
\hline & 4 & Levenberg-Marquardt & 0.986 & 0.926 & 0.982 & 3.89 & 1.62 & 2.47 \\
\hline & 5 & Levenberg-Marquardt & 0.987 & 0.968 & 0.979 & 2.81 & 1.69 & 2.05 \\
\hline & 6 & Levenberg-Marquardt & 0.989 & 0.981 & 0.983 & 2.97 & 1.59 & 1.96 \\
\hline & 7 & Levenberg-Marquardt & 0.991 & 0.979 & 0.985 & 2.40 & 1.47 & 1.81 \\
\hline & 8 & Levenberg-Marquardt & 0.989 & 0.976 & 0.988 & 2.38 & 1.46 & 1.83 \\
\hline & 9 & Levenberg-Marquardt & 0.986 & 0.940 & 0.979 & 2.87 & 1.49 & 1.80 \\
\hline & 10 & Levenberg-Marquardt & 0.990 & 0.946 & 0.986 & 2.00 & 1.41 & 1.59 \\
\hline & 3 & Scaled Conjugate Gradient & 0.958 & 0.957 & 0.957 & 3.28 & 1.45 & 2.02 \\
\hline & 4 & Scaled Conjugate Gradient & 0.975 & 0.857 & 0.966 & 2.96 & 1.62 & 2.04 \\
\hline & 5 & Scaled Conjugate Gradient & 0.967 & 0.892 & 0.953 & 2.75 & 1.43 & 1.99 \\
\hline & 6 & Scaled Conjugate Gradient & 0.980 & 0.956 & 0.977 & 2.64 & 1.54 & 2.04 \\
\hline & 7 & Scaled Conjugate Gradient & 0.982 & 0.965 & 0.979 & 2.96 & 1.70 & 2.17 \\
\hline & 8 & Scaled Conjugate Gradient & 0.979 & 0.978 & 0.978 & 2.69 & 1.60 & 2.03 \\
\hline & 9 & Scaled Conjugate Gradient & 0.984 & 0.957 & 0.979 & 3.43 & 1.59 & 2.23 \\
\hline & 10 & Scaled Conjugate Gradient & 0.974 & 0.953 & 0.972 & 3.13 & 1.52 & 2.09 \\
\hline & 3 & BFGS Quasi-Newton & 0.949 & 0.841 & 0.937 & 4.70 & 2.05 & 3.53 \\
\hline & 4 & BFGS Quasi-Newton & 0.958 & 0.931 & 0.951 & 5.00 & 2.89 & 3.79 \\
\hline & 5 & BFGS Quasi-Newton & 0.962 & 0.888 & 0.951 & 5.39 & 2.68 & 3.67 \\
\hline & 6 & BFGS Quasi-Newton & 0.980 & 0.871 & 0.952 & 5.23 & 2.85 & 3.74 \\
\hline & 7 & BFGS Quasi-Newton & 0.966 & 0.945 & 0.957 & 4.91 & 2.97 & 3.84 \\
\hline & 8 & BFGS Quasi-Newton & 0.979 & 0.943 & 0.973 & 5.75 & 2.43 & 4.13 \\
\hline & 9 & BFGS Quasi-Newton & 0.972 & 0.957 & 0.964 & 5.73 & 2.95 & 4.11 \\
\hline & 10 & BFGS Quasi-Newton & 0.978 & 0.890 & 0.969 & 6.16 & 3.00 & 4.28 \\
\hline \multirow{24}{*}{$\begin{array}{l}\text { Roughness } \\
\text { Ra }\end{array}$} & ANN & Levenberg-Marquardt & 0.972 & 0.274 & 0.884 & 9.09 & 2.75 & 5.86 \\
\hline & 4 & Levenberg-Marquardt & 0.973 & 0.550 & 0.926 & 7.98 & 1.71 & 3.87 \\
\hline & 5 & Levenberg-Marquardt & 0.973 & 0.830 & 0.964 & 4.25 & 1.46 & 2.55 \\
\hline & 6 & Levenberg-Marquardt & 0.973 & 0.962 & 0.971 & 4.74 & 1.49 & 2.47 \\
\hline & 7 & Levenberg-Marquardt & 0.973 & 0.902 & 0.970 & 3.47 & 1.42 & 2.11 \\
\hline & 8 & Levenberg-Marquardt & 0.973 & 0.951 & 0.968 & 5.25 & 1.38 & 2.10 \\
\hline & 9 & Levenberg-Marquardt & 0.973 & 0.403 & 0.937 & 4.59 & 1.43 & 2.13 \\
\hline & 10 & Levenberg-Marquardt & 0.973 & 0.876 & 0.966 & 4.76 & 1.51 & 2.35 \\
\hline & 3 & Scaled Conjugate Gradient & 0.844 & 0.746 & 0.817 & 9.37 & 6.09 & 7.51 \\
\hline & 4 & Scaled Conjugate Gradient & 0.972 & 0.143 & 0.849 & 8.37 & 5.74 & 7.35 \\
\hline & 5 & Scaled Conjugate Gradient & 0.964 & 0.764 & 0.950 & 8.79 & 6.93 & 7.59 \\
\hline & 6 & Scaled Conjugate Gradient & 0.972 & 0.524 & 0.947 & 8.00 & 5.88 & 6.98 \\
\hline & 7 & Scaled Conjugate Gradient & 0.972 & 0.760 & 0.933 & 7.89 & 5.42 & 7.07 \\
\hline & 8 & Scaled Conjugate Gradient & 0.973 & 0.968 & 0.971 & 7.94 & 4.75 & 6.84 \\
\hline & 9 & Scaled Conjugate Gradient & 0.973 & 0.967 & 0.973 & 9.09 & 6.51 & 7.91 \\
\hline & 10 & Scaled Conjugate Gradient & 0.973 & 0.948 & 0.964 & 9.24 & 6.36 & 8.06 \\
\hline & 3 & BFGS Quasi-Newton & 0.914 & 0.547 & 0.848 & 9.89 & 3.30 & 7.11 \\
\hline & 4 & BFGS Quasi-Newton & 0.973 & 0.401 & 0.954 & 11.36 & 3.24 & 8.38 \\
\hline & 5 & BFGS Quasi-Newton & 0.972 & 0.915 & 0.963 & 11.35 & 5.22 & 8.92 \\
\hline & 6 & BFGS Quasi-Newton & 0.974 & -0.271 & 0.929 & 11.04 & 5.73 & 8.85 \\
\hline & 7 & BFGS Quasi-Newton & 0.971 & 0.786 & 0.933 & 11.07 & 6.77 & 9.16 \\
\hline & 8 & BFGS Quasi-Newton & 0.973 & 0.648 & 0.951 & 11.62 & 5.94 & 9.01 \\
\hline & 9 & BFGS Quasi-Newton & 0.973 & -0.187 & 0.934 & 11.64 & 6.35 & 9.47 \\
\hline & 10 & BFGS Quasi-Newton & 0.974 & 0.724 & 0.949 & 11.91 & 6.66 & 9.69 \\
\hline
\end{tabular}

\section{References}

1. The Nobel Prize, Press Release. The Nobel Prize in Chemistry. Available online: https://www.nobelprize.org/ prizes/chemistry/2016/press-release/ (accessed on 14 April 2019).

2. Sutoova, A.; Zgodavová, K. Future of Needs for Learning and Development, in Q-MOD'2019, Leadership and strategies for Sustainable Quality and Innovation in the 4th Industrial Revolution. In Proceedings of the Maturity of Automotive Industry 4.0 and Quality 4.0 Intelligent Technology in Slovakia, Lund, Sweden, 13-15 October 2019.

3. Jakob, T. A 5-Step Approach towards Successful Industry 4.0 Projects. Bosch ConnectedWorld Blog. Available online: https://blog.bosch-si.com/industry40/a-5-step-approach-towards-successful-industry-4-0-projects/ (accessed on 5 June 2019).

4. Šibalija, T.; Majstorovic, V. Advanced Multiresponse Process Optimisation: An Intelligent and Integrated Approach; Springer: Berlin/Heidelberg, Germany, 2016; p. 65.

5. Bravi, L.; Murmura, F.; Santos, G. Manufacturing labs: Where new digital technologies help improve life quality. Int. J. Qual. Res. 2018, 12, 957-974. [CrossRef] 
6. Santos, G.; Gomes, S.; Braga, V.; Braga, A.; Lima, V.; Teixeira, P.; Sá, J. Value creation through quality and innovation-A case study on Portugal. TQM J. 2019, 31, 928-947. [CrossRef]

7. Isaksson, R. Economic sustainability and the cost of poor quality. Corp. Soc. Responsib. Environ. Manag. 2005, 12, 197-209. [CrossRef]

8. Krolczyk, G.; Nieslony, P.; Maruda, R.; Wojciechowski, S. Dry cutting effect in turning of a duplex stainless steel as a key factor in clean production. J. Clean. Prod. 2017, 142, 3343-3354. [CrossRef]

9. Zgodavová, K.; Slimák, I. Advanced Improvement of Quality in Annals of DAAAM E Proceedings of the 19th International DAAAM Symposiu; Katalinc, B., Ed.; DAAAM International: Vienna, Austria, 2008; pp. 1551-1553.

10. Jarošová, E.; Noskievičová, D. Pokročilejší Metody Statistické Regulace Procesu; Grada Publishing, a.s.: Prague, Czech Republic, 2015. (In Czech)

11. ISO 7870-8:2017. Charting Techniques for Short Runs and Small Mixed Batches; ISO: Geneva, Switzerland, 2017.

12. Ustyguová, T.; Noskievičová, D. Integration of lean and agile manufacturing based on principles from wikinomics. Qual. Innov. Prosper. 2013, 17, 48-56. [CrossRef]

13. Zell, S. How Six Sigma Supports Sustainable Business Practice. Available online: https://www.sixsigmadaily. com/six-sigma-inherently-supports-sustainable-business-practice/ (accessed on 15 May 2020).

14. Zimon, G.; Zimon, D. The Impact of Implementation of Standardized Quality Management Systems on Management of Liabilities in Group Purchasing Organizations. Qual. Innov. Prosper. 2019, 23, 60-73. [CrossRef]

15. Vertical Data Analytics, Process. Available online: https://www.verticaldata.com/process/ (accessed on 12 June 2019).

16. ISO 9001:2015. Quality Management Systems_Requirements; ISO: Geneva, Switzerland, 2015.

17. Castro, M.; Posada, L. Implementation of lean manufacturing techniques in the bakery industry in Medellin. Gestão Produção 2019, 26, e2505. [CrossRef]

18. Hossain, M. A Study to Reduce the Lead Time of a Bakery Factory by Using Lean Tools: A Case Study. Int. J. Sci. Res. Public 2015, 5, 249-256.

19. Kaid, H.; Noman, M.; Nasr, E.; Alkahtani, M. Six Sigma DMAIC phases application in Y company: A case study. Int. J. Collab. Enterp. 2016, 5, 181-197. [CrossRef]

20. DEAR Systems, 8 Powerful Lean Six Sigma Tools for Streamlined Manufacturing. Available online: https://dearsystems.com/lean-six-sigma/ (accessed on 6 June 2019).

21. Park, S.; Dahlgaard-Park, S.; Kim, D.-C. New Paradigm of Lean Six Sigma in the 4th Industrial Revolution Era. Qual. Innov. Prosper. 2020, 24, 1-16. [CrossRef]

22. Debbagh, S. How Operational Intelligence and Lean Six Sigma Improve Business Processes. Available online: https://apifriends.com/api-analytics/operational-intelligence-and-lean-six-sigma/ (accessed on 5 April 2019).

23. Turisová, R.; Pačaiová, H. Inžinierstvo Kvality Produkcie; Technická univerzita v Košiciach: Košice, Slovakia, 2015.

24. Jurkovic, Z.; Cukor, G.; Brezocnik, M.; Brajkovic, T. A comparison of machine learning methods for cutting parameters prediction in high speed turning process. J. Intell. Manuf. 2018, 29, 1683-1693. [CrossRef]

25. Karayel, D. Prediction and control of surface roughness in CNC lathe using artificial neural network. J. Mater. Process. Technol. 2008, 209, 3125-3137. [CrossRef]

26. Berardinelli, C. Short-Run Statistical Process Control Techniques. ISIXSIGMA. Available online: https://www. isixsigma.com/tools-templates/control-charts/short-run-statistical-process-control-techniques/ (accessed on 4 May 2020).

27. M\&S Machine Company, Ltd., Predictive Statistical Control. Available online: https://www.lsmachineco.com/ (accessed on 17 July 2020).

28. Zorriassatine, F.; Tannock, J. A review of neural networks for statistical process control. J. Intell. Manuf. 1998, 9, 209-224. [CrossRef]

29. Psarakis, S. The Use of Neural Networks in Statistical Process Control Charts. Qual. Reliab. Eng. 2011, 27, 641-650. [CrossRef]

30. Zan, T.; Liu, Z.; Su, Z.; Wang, M.; Gao, X.; Chen, D. Statistical Process Control with Intelligence Based on the Deep Learning Model. Appl. Sci. 2020, 10, 308. [CrossRef]

31. Sahasrabudhe, A.; Ratnam, M. Prediction of surface roughness and dimensional deviation by measuring cutting forces and vibrations in turning process. Int. J. Adv. Manuf. Technol. 2010, 48, 213-226. [CrossRef] 
32. Routara, B.; Bandyopadhyay, A.; Sahoo, P. Roughness modeling and optimization in CNC end milling using response surface method: Effect of workpiece material variation. Int. J. Adv. Manuf. Technol. 2009, 40, 1166-1180. [CrossRef]

33. Cakir, M. Mathematical modeling of surface roughness for evaluating the effects of cutting parameters and coating material. J. Mater. Process. Technol. 2009, 209, 102-109. [CrossRef]

34. Grzesik, W. A revised model for predicting surface roughness in turning. Wear 1996, 194, 143-148. [CrossRef]

35. Azouzi, R.; Guillot, M. On-line prediction of surface finish and dimensional deviation in turning using neural network based sensor fusion. Int. J. Mach. Tools Manuf. 1997, 37, 1201-1217. [CrossRef]

36. Benardos, P.; Vosniakos, G. Predicting surface roughness in machining: A review. Int. J. Mach. Tools Manuf. 2003, 43, 833-844. [CrossRef]

37. Lu, C.; Costes, J. Surface profile prediction and analysis applied to turning process. Int. J. Mach. Mach. Mater. 2008, 4, 158-180. [CrossRef]

38. Dhas, J.; Stalin, R.; Rajeesh, J. RBF neural network model for machining quality prediction in CNC turning process. Int. J. Model. Identif. Control. 2013, 20, 174. [CrossRef]

39. Krolczyk, G.; Gajek, M.; Legutko, S. Predicting the tool life in the dry machining of duplex stainless steel. Eksploat. Niezawodn. 2013, 15, 62-65.

40. Nugent, P. Shaft Measurement: What is the Best Tool for the Job? Qual. Mag. 2019, 58, $20-23$.

41. Montgomery, D. Design and Analysis of Experiments; Wiley: New York, NY, USA, 2001.

42. Sun, Q.; Dong, N.; Chen, Z.; Yuan, Z. A modified neural network based predictive control for non-linear systems. Int. J. Model. Identif. Control. 2009, 8, 91-97. [CrossRef]

43. Goodfellow, I.; Bengio, Y.; Courville, A. Deep Learning (Adaptive Computation and Machine Learning Series); The MIT Press: Cambridge, UK, 2016; pp. 200-223.

44. Mozammel, M.; Królczyk, G.; Maruda, R.; Wojciechowski, S. Intelligent Optimization of Hard-Turning Parameters Using Evolutionary Algorithms for Smart Manufacturing. Materials 2019, 12, 879. [CrossRef]

45. Lee, W.; Lau, H. Factory on demand: The shaping of an agile production network. Int. J. Agil. Manag. Syst. 1999, 2, 83-87. [CrossRef] 